\title{
Techniques for Wound Healing with a Focus on Pressure Ulcers Elimination
}

\author{
Damien P. Kuffler*
}

Institute of Neurobiology, University of Puerto Rico, 201 Blvd. del Valle, San Juan, PR 00901, USA

\begin{abstract}
Pressure ulcers, also called decubitus ulcers, are a common challenge of humanity. They are wounds initiated by pressure on the skin that blocks circulation causing the skin and underlying tissues to die. Without care, pressure ulcers continue to grow in diameter and depth and are exceptionally difficult to heal. They have probably always existed, and are present on Egyptian mummies. Pressure ulcers are a serious health issue, very painful, a significant physiological challenge, can shorten the life of a patient, are an emotional and financial burden to the patient, those who deal with them, and in the United States alone annually costs in excess over $\$ 10$ billion dollars for care and prolonged hospitalization. Pressure ulcers can develop with as little as two hours of pressure, and because even a brief lapse in avoidance of pressure leads to ulcers, they are frequently impossible to prevent, even for the most conscientious patient with an extensive support group and unlimited financial resources. Therefore, enormous effort is required to find effective and reliable techniques for preventing the initiation of ulcers and eliminating them once they develop. This review looks at the various approaches presently used and in development for the treatment of pressure ulcers, evaluates which may be best in eliminating ulcers, and discusses combinations of techniques that may be most effective in eliminating pressure ulcers.
\end{abstract}

Keywords: Pressure ulcers, chronic sores, electrical stimulation, platelet-rich fibrin, hyperbaric , oxygenation.

\section{INTRODUCTION}

Pressure ulcers, also called decubitus ulcers, were first seriously studied by Jean-Martin Charcot, a clinician in the 19th century [1-3]. He proposed that pressure or local irritation were not the causative factors for the decubitus, but rather, that damage to the central nervous system led directly to the ulcers, a concept he called the "neurotrophic theory."

Charcot observed that many patients who developed eschar of the sacrum and buttocks died soon afterwards, and referred to this lesion as the decubitus ominosus, implying that the development of an ulcer was a sign of impending death [2]. Although methods for dealing with pressure ulcers improved significantly, there is still no reliable method for eliminating them. Physicians of ancient Egypt were experts in the art and science of healing wounds, as is revealed in the Smith Papyrus, one of the oldest medical texts in existence [4]. Today, wound healing is no longer emphasized in medical training and practice, while wound care is becoming increasingly important to geriatricians and long-term care providers. Although there are an extremely diverse number of ways to approach pressure ulcer prevention healing and prevention none is optimal $[2,5,6]$.

Development and treatment of pressure ulcers are for all of us at some time in our lives a great concern. This may arise from an infirmity which leaves us immobilized for a prolonged time, or dealing with aging family members or friends who spend long periods immobile in bed. In each of

*Address correspondence to this author at the Institute of Neurobiology, 201 Blvd. del Valle, San Juan, PR 00901, USA; Tel: 787-721-1235;

Fax: 787-725-1289; E-mail: dkuffler@hotmail.com these cases, the opportunity is present to develop a pressure, which can often lead to a rapid deterioration of lifestyle and death.

This short review examines the etiology of pressure ulcers, some treatments used to treat them, and provides insights into potential new approaches that might provide faster and more reliable methods for ulcer elimination.

\section{ETIOLOGY}

Many factors contribute to the development of pressure sores: being elderly, the inability to move certain parts of your body without assistance (such as after spinal or brain injury), a neuromuscular disease (such as multiple sclerosis), malnourishment, being bedridden or in a wheelchair, having a chronic disease condition (such as diabetes or vascular disease), urinary incontinence or bowel incontinence, fragile skin, or a mental disability [7, 8]. Malnutrition [9], hypoproteinemia [10], and anemia [11,12] reflect the overall status of the patient and can contribute to vulnerability of tissue and delays in ulcer [13] wound healing. Poor nutritional status contributes to the chronicity often observed with these lesions. Anemia indicates poor oxygen-carrying capacity of the blood. Bacterial contamination, from improper skin care or urinary or fecal incontinence, is an important factor to consider in the treatment of pressure sores because it can delay wound healing. However, the initial management of a pressure ulcer should include removal of the pressure source.

The final common pathway to ulcerization is that tissues can withstand, for only a brief duration, pressure slightly above capillary filling pressure, and such pressure initiates a downward spiral towards ulceration. Capillaries, have pressure on the arterial side of around $30-32 \mathrm{~mm} \mathrm{hg}$, and on 
the venous side of around $12 \mathrm{~mm} \mathrm{hg}$, with sustained pressures higher than these causing microcirculatory occlusion as pressures rise above capillary filling pressure. This results in the interruption of blood supply to the skin [14], and the resulting ischemia leads to inflammation and tissue anoxia. Tissue anoxia leads to cell death, necrosis, and ulceration. Uninterrupted pressure for as little as 2 hours can cause irreversible changes leading to the development of an ulcer.

The loss of cutaneous sensitivity contributes to ulceration by removing one of the most important warning signals about excess pressure, pain [15]. Paralysis leads to atrophy of the skin with thinning of this protective barrier, making the skin more susceptible to minor traumatic forces, such as friction and shear forces that are exerted during moving a patient $[16,17]$. Trauma causing de-epithelialization leads to transdermal water loss, creating maceration and adherence of the skin to clothing and bedding, which raises the coefficient of friction for further insult [16] .

Pressure ulcers are one of the most severe complications for spinal cord injury patients. Ulcers are also an extreme complication for diabetics, and diabetes mellitus significantly retards wound healing.

\section{CLINICAL IMPLICATIONS OF ULCERS}

Soft tissues, muscle, and skin have a differential resistance to the effects of pressure. Generally, muscle is the least resistant and will necrose prior to skin breakdown. In addition, pressure is not distributed equally from the bony surface to the overlying skin, with pressure being greatest at the bony prominence and decreasing gradually towards the periphery. Once a small area of skin breakdown has occurred, one is only the tip of the iceberg, with typically a large cavity and extensive undermining of the skin edges.

Pressure ulcers classification typically involves 4 stages of ulceration designed to describe the depth of a pressure sore at the specific time of examination [18-20]. Stage I represents intact skin with signs of impending ulceration that can be resolved within 24 hours of the removal of pressure, while continued pressure creates erythema that does not blanch with pressure, and the skin may appear white from ischemia. Stage II represents a partial-thickness loss of skin involving epidermis and possibly dermis, which may present as an abrasion, blister, or superficial ulceration. Stage III represents the loss of a full-thickness of skin with extension into subcutaneous tissue but not through the underlying fascia, which presents as a crater with or without undermining of adjacent tissue. Stage IV represents fullthickness loss of skin and subcutaneous tissue and extension into muscle, bone, tendon, or joint capsule. Osteomyelitis with bone destruction, dislocations, or pathologic fractures may be present.

The most common places for pressure ulcers are over bony prominences (bones close to the skin) like the elbow, heels, hips, ankles, shoulders, back, and back of the head [16]. The hip and buttock regions account for $67 \%$ of all pressure sores, with ischial tuberosity, trochanteric, and sacral locations being most common. The lower extremities account for an additional $25 \%$ of all pressure sores, with malleolar, heel, patellar, and pretibial locations being most common. The remaining approximately $10 \%$ of pressure sores may occur in any location that experiences long periods of uninterrupted pressure. No surface of the body is immune to the effects of pressure.

\section{CUTANEOUS INSENSITIVITY DUE TO SHORT PE- RIODS OF CLINICALLY REQUIRED NERVE BLOCK INDUCE ULCERS}

Following total knee replacement surgery, femoral and sciatic nerve blocks are often used for postoperative analgesia. In some instances, the resulting heel ulcers result in delayed rehabilitation and prolonged hospital, making this phenomenon a burden on the healthcare system [21]. To prevent pressure ulcers, protection of foot pressure points is critical after the implementation of nerve blocks. An awareness of this unusual complication related to knee replacement surgery is necessary to prevent its occurrence and avoid delays in patient rehabilitation and recovery [22, 23].

Severe neurologic damage is the major determining factor in predicting neurologic recovery. Pressure ulcer prevention is statistically associated with neurologic improvement and the shortening of rehabilitation. Patient management immediately before admission to rehabilitation has a statistical correlation with neurologic improvement in all patients studied and on both rehabilitation and incidence of pressure ulcers in the neurotrauma and spinal cord injury patients [24].

\section{PREVALENCE OF ULCERS}

A number of studies have examined the prevalence of pressure ulcers in hospitalized or institutionalized patients, all with similar results [25-28]. Patients hospitalized with acute illness have an incidence rate for pressure ulcers of 3 $11 \%$. In 2003, $6.9 \%$, and in 2004, $7 \%$ of patients had pressure ulcers at start of health care. Of these, $23 \%$ were Stage III or Stage IV and $31 \%$ were "not healing." Two thirds of pressure sores occur in patients older than 70 years with a prevalence rate in nursing homes of about $17-28 \%$. Among patients who are neurologically impaired, pressure sores occur with an annual incidence of 5-8\%, with lifetime risk estimated to be $25-85 \%$. Moreover, pressure sores are listed as the direct cause of death in $7-8 \%$ of all paraplegics. Disturbingly, even with current medical and surgical therapies, patients who achieve a healed wound have recurrence rates of as high as $90 \%$

\section{TESTED METHODS FOR THE ELIMINATION OF PRESSURE ULCERS}

\section{Ulcer Care}

The current standard methods of pressure ulcer treatment are aimed at removing necrotic debris, controlling infection, and relieving chronic pressure on the wound. Unfortunately, healing rates are poor with standard treatment, averaging 1220 weeks in clinical trials [25]. The general hope is for the living tissue to release appropriate quantities of growth factors, cytokines and other proteins to stimulate the chronic wound bed and accelerate healing. New therapeutic strategies are being developed and improved for eliminating pressure ulcers, which include skin replacement using 
biological skin substitutes, growth factors, laser, hyperbaric oxygen, electrical stimulation and negative pressure dressings.

\section{Cleaning}

Many clinicians use normal saline to cleanse the periwound skin and the wound bed itself. However, normal saline solutions do not effectively remove skin debris such as water-insoluble proteins and lipids [29-31]. One study analyzed the skin debris and microorganisms found on the periwound skin of Stage III and IV pressure ulcers compared to normal skin. In addition, microorganisms from the wound bed, periwound, and normal skin were collected before, immediately after, and 6 hours and 24 hours after periwound cleansing using a skin cleanser. A further comparison was made of the influences of periwound skin cleansed with normal saline for one year followed in year two by cleansing with a pH-balanced cleanser, vs. the constant use of the cleanser. The cleanser resulted in 1.8-fold shorter healing time for every stage of ulcer [32]. However, overall, there is no good trial evidence to support use of any particular wound cleansing solution or technique for pressure ulcers [33].

\section{SILVER CONTAINING DRESSINGS}

Microorganisms in wounds retard or prevent healing. Prevention and treatment of wound colonisation or infection can be achieved by using silver-based dressings, which have been used as an antimicrobial agent for centuries [34]. They are effective against a broad range of bacteria (including methicillin and vancomycin-resistant strains), yeast, fungi and viruses $[35,36]$. A silver-releasing hydroalginate dressing (Silvercel) induces significantly better wound healing than pure calcium alginate dressing (Algosteril) [37]. A number of silver-based dressings, some of which act by the sustained release of silver ions to the wound bed, are available, and there are wide variations in the amount of data supporting the use of individual products. Some of these dressings frequently induce burning and stinging on application.

Hydrofiber $(\mathrm{R})$ which is combined with a silver dressing reduces these painful actions induced by some other dressings [38]. It also leads to the resolution of periwound maceration in $85 \%$ of the patients, and reduces the bacterial burden of the wound [38]. An additional influence is the $70 \%$ decrease in wounds size and decreased exudate, decreased purulence and resolution of surface slough [38].

\section{HYDROPOLYMER TO IMPROVE OR PREVENT PRESSURE ULCERS}

Effective pressure ulcer management requires a dressing that maintains a moist environment, to facilitate healing, absorb exudate, remain in place for a number of days, reduce the number of required dressing changes, prevent trauma to the surrounding skin and reduce the costs of ulcer management. One such material is a self-adhesive hydropolymer foam dressing that is a one-piece, multilayer, highly absorbent, non-adherent wound dressing contact layer (Tielle, Johnson \& Johnson) [39]. Alione Hydrocapillary dressing (Coloplast A/S), and two hydropolymer dressings, Tielle and Tielle Plus, have relatively equal effectiveness in ulcer healing (Johnson \& Johnson) [39]. Tielle induces better healing, especially of heal ulcers (50-77\%), compared the effects of a soft silicone dressing (44\%) [37, 40, 41]. This design makes dressing changes less painful and traumatic [42]. However, a soft silicone dressing is effective than the hydropolymer dressing in reducing damage to the surrounding skin, maceration, and dressing removal difficulties [37, 40].

\section{CALCIUM ALGINATE DRESSINGS}

Exuding wounds, such as leg ulcers, pressure sores and infected surgical wounds are extensively treated with alginate dressings, primarily formed of calcium alginate fibers [43-45]. Improvements in calcium alginate dressings have been made by making them into a more cohesive structure with increased strength and greater gelling capacity, provided by sodium alginate, when it is soaked with exudate or blood.

Calcium alginate dressings (UrgoSorb) plus hydrocolloid dressings (Algoplaque) induce more rapidly healing of such wounds compared to controls [46-48]. Once in contact with an exuding wound, an ion-exchange reaction takes place between the calcium ions in the dressing and sodium ions in serum or wound fluid [47]. When a significant proportion of the calcium ions on the fiber has been replaced by sodium, the fiber swells and partially dissolves forming a gel-like mass. The degree of swelling is determined principally by the chemical composition of the alginate, which depends on its botanical source. Such dressings provide advantages over traditional dressings for some clinical indications.

\section{SHEAR FORCE INDUCED BY DRESSINGS}

Shear force enhances the incidence of the development of pressure ulceration. Therefore, dressing materials that reduce shear force against the skin reduce ulceration and facilitate healing $[16,49]$.

\section{Hydrogel Treatment}

Hydrogel dressing combined with a conservative topical wound-care regimen (gauze with povidone-iodine) have been used for the treatment of pressure ulcers [50]. The differences in the healing rates were not statistically significant [51]. However, hydrogel dressing lead to $84 \%$ of the ulcers becoming epithelialized compared to $54 \%$ in the control group, although the healing time was not different [51]. Thus, hydrogel occlusive wound dressings facilitate healing by promoting more rapid epithelialization of pressure ulcers, when compared with conservative wound care.

\section{Collagen}

Collagen plays a major role in wound healing $[52,53]$. Its presence is important in all stages of the healing process. Catrix is a new collagen wound-healing powder is effective in the treatment of wounds healing by secondary intent such as pressure ulcers, venous stasis ulcers and diabetic ulcers, as well as second-degree burns and post-radiation dermatitis $[54,55]$. Catrix is also effective in the treatment of wounds unresponsive to conventional treatments by promoting the growth of fibroblasts and keratinocytes in the wound, prevents loss of fluid from the wound and protects the wound from bacterial infections and other agents. Because it 
is biodegradable, Catrix does not require removal from the wound bed before re-application [54].

\section{Growth Factors}

In animal models, exogenous application of growth factors has been reported to accelerate healing of chronic wounds [56-61]. Most of the trials have been of brief duration with short to no follow-up periods. The long-term outcome for ulcer patients is better with growth factor application than with surgical or standard non-operative treatment of pressure ulcers. Patients receiving exogenously applied cytokines achieved $>85 \%$ closure during the treatment [56, 62]. However, the extremely limited number of FDA-approved growth factors has limited the possibilities of performing large-scale clinical trials. Further, all studies to date have tested the influences of only single factors at a time. However, future wound dressings will most likely include several growth factors, with each serving a specific function.

\section{Platelet Derived Growth Factor}

Platelets play an essential role in wound healing because they contain and release a host of alpha-granule growth factors (platelet derived growth factor, PDGF; transforming growth factor-beta, TGF-beta; vascular endothelial growth factor, VEGF) $[63,64]$.

PDGF is the most researched of all the growth factors, and was originally studied in the management of pressure ulcers [58, 63, 65], and was eventually approved in North America for the treatment of diabetic lower extremity ulcers $[66,67]$. PDGF promotes chemotaxis of neutrophils, monocytes and smooth muscle cells in wounds. Topical application of recombinant PDGF speeds wound healing and promotes granulation tissue formation, synthesis of extracellular matrix and the inflammatory phase of the wound healing process in healthy and healing-impaired animal models and clinical trials [68]. Platelet gel hemocomponent, obtained from mix of activated platelets and cryoprecipitate, allows the topical application of exogenous growth factors and accelerates the healing of chronic ulcers [39, 69, 70]. It also eliminated pain in all patients in one study [69]. Increasing the relative ratio of transforming growth factor (TGF)beta-3 to TGFbeta-1 and TGFbeta-2 applied to ulcers minimizes scarring [63, 71]. Although topical platelet-derived growth factor has demonstrated benefit in some studies, its use remains controversial [14].

Becaplermine gel (Regranex) is an hydrogel which contains $100 \mu \mathrm{g}$ of recombinant PDGF per gram, and the $0.01 \%$ Regranex gel with single daily application is currently the only commercially available topical growth factor for use in cutaneous wound healing $[68,72]$. It has been approved as adjuvant treatment for neuropathic diabetic ulcerations of less than $5 \mathrm{~cm}^{2}$, extending into the subcutaneous tissue, in the absence of ischemia, in conjunction with a standardized program of appropriate wound care, (control of infection, sharp debridement, provision of a moist environment and avoidance of pressure on the wound). PDGF promotes cutaneous wound healing by increasing proliferation and migration of dermal fibroblasts and extracellular matrix deposition [68].

\section{Topical Application of Nerve Growth Factor (NGF)}

In an animal model study, topical application of NGF to wounds and ulcers leads to a statistically significant decrease in the perimeter of the wound $(66 \%)$ compared to the control group [73-76]. Clinically, topical application of NGF leads to the repair of neurotrophic corneal ulcers and recovery of corneal surface sensitivity $[77,78]$ and to diabetic foot ulcers [79].

\section{Basic Fibroblast Growth Factor (bFGF)}

Topical application of bFGF enhances the healing for operative wounds, burns, chronic dermal and diabetic ulcers about 2-fold faster than untreated wounds [57, 80-83]. It is proposed that this influence is by inducing proliferation of reparative cells, which are otherwise non-proliferating

\section{Transforming Growth Factor-beta}

The pathology of chronic dermal ulcers is characterized by excessive proteolytic activity, which degrades extracellular matrix (required for cell migration) and growth factors and their receptors. Transforming growth factor-beta (TGF-beta) is a key signal in orchestrating wound repair [63, 64, 84, 85]. Targeting TGF-beta using antisense oligonucleotides on the expression of these factors in human keratinocytes results in a decreased expression of bFGF and VEGF in chronic dermal wounds compared to normal human skin [61, 64]. Antisense TGF-beta oligonucleotide treatment down-regulated collagenase secretion activity and upregulate VEGF secretion in vitro. Therefore, TGF-beta antisense oligonucleotide technology may be a potential therapeutic option for the inhibition of proteolytic tissue destruction, and stimulation of angiogenesis in chronic wounds [61, 69]. See [63] for a recent review.

Non-steroidal anti-inflammatory drugs delay ulcer healing and cause refractory peptic ulcers in humans. In an animal model, indomethacin delayed ulcer healing but transforming growth factor-beta and famotidine improved ulcer healing and reversed the effects of indomethacin [86].

\section{Recombinant Human Erythropoietin}

Impaired tissue oxygenation, with hemoglobin greater $\geq 100 \mathrm{~g} / \mathrm{L}$, makes ulcer healing difficult. Decreased hemoglobin often results from anemia due to a chronic disease and may be due to the effects of inflammatory cytokines on erythroid progenitor cells. Subcutaneous administration of recombinant human erythropoietin (75 IU/kg), 3 times weekly for 6 weeks, leads to the resolution of refractory anemia of chronic disease and healing of Stage IV pressure ulcers of spinal cord patients [11]. The treatment results in a mean hemoglobin increase from 88 to $110 \mathrm{~g} / \mathrm{L}$, with a $22 \%$ decrease in mean ulcer surface area and $50 \%$ decrease in mean ulcer depth $[11,87]$.

\section{Essential Fatty Acids}

A patients' good nutritional status is essential for wound healing to take place. Protein deficiency has been demonstrated to contribute to poor healing rates with reduced collagen formation and wound dehiscence [88-91]. Skin beak-down resulting in high exudate loss can result in a deficit of as much as $100 \mathrm{gm}$ of protein in one day [88]. There is a correlation between low serum albumin and body 
mass index (BMI) and the development of pressure ulcers [92].

The topical application of essential fatty acids to the entire body, including potential wound sites, improves tissue hydration and elasticity and helps prevent skin breakdown in individuals with a poor nutritional status [89, 93]. This application results in a 36\% reduction in the development of pressure ulcers [93]. The influences of the topical application of essential fatty acids may be especially effective for the severely malnourished.

\section{METALLOPROTEINASE INHIBITORS: SYNTHESIS AND SUPPRESSION OF INFLAMMATORY CYTO- KINES}

The pathology of chronic dermal ulcers is characterized by excessive proteolytic activity, which degrades the extracellular matrix (required for cell migration), growth factors and their receptors [94]. The over expression of metalloproteinase-3 (MMP-3) (stromelysin-1) and MMP-13 (collagenase-3) is associated with non-healing wounds, whereas active MMPs-1, -2, -9, and -14 are required for normal wound healing to occur $[64,95,96]$. The synthetic metalloproteinase inhibitor, $\mathrm{HSCH} 2 \mathrm{CH}[\mathrm{CH} 2 \mathrm{CH}(\mathrm{CH} 3) 2]$ CO-Phe-Ala-NH2 (SIMP) is effective in neutralizing the metalloprotease MMP-3 and MMP-13, but not MMPs-1, -2, -9 and -14 [97]. Therefore, SIMP can be used to eliminate MMP-3 and -13 , while allowing normal wound healing to take place [97].

The fluids of chronic, non-healing wounds contain elevated levels of inflammatory cytokines, such as interleukin (IL)-1alpha and IL-6, elevated levels of proteinases, and low levels of growth factor activity compared with fluids collected from acute, healing wounds $[95,98]$. The ratio of activated matrix metalloproteinase- 9 to tissue inhibitor of matrix metalloproteinase-1 in wound fluids is inversely correlated with healing of pressure ulcers [95]. This led to the hypothesis that chronic inflammation in acute wounds produces elevated levels of proteinases that destroy essential growth factors, receptors, and extracellular matrix proteins, which ultimately prevent wounds from healing.

Wounds that healed well had a significantly lower ratio of pro- and activated matrix metalloproteinases, than the tissue inhibitors of metalloproteinases, compared to wounds that did not heal well [95]. Thus, the ratio of pro- and activated matrix metalloproteinases, to tissue inhibitors of metalloproteinases is a predictor of healing in pressure ulcers [99]. This suggests that reducing pro- and activated matrix metalloproteinase and increasing the level of activity of tissue inhibitors of metalloproteinases would lead to improved wound healing.

\section{Hydrolysate Supplement}

An alternative medication for pressure ulcers is a concentrated, fortified, collagen protein hydrolysate supplement. After 8 weeks of treatment this induces approximately twice the rate of pressure ulcer healing compared to control patients, healing in about 70 days, with the ulcers of $63 \%$ of the treated patients healing $[53,100]$.

\section{High Pressure Treatment}

Chronic venous insufficiency (CVI) causes a welldefined microangiopathy described as venous hypertensive microangiopathy (VHM) leading to venous stasis ulcerations [101-103]. White cell activation, protein leakage from pressurized capillaries, and cytokine imbalances have all been implicated as indirect effects of venous hypertension that contribute to dermal changes seen in chronic venous insufficiency. The direct effect of increased tissue pressures on dermal elements can be demonstrated by placing these cells in vitro under high vs. atmospheric pressure. Cells grown under pressure have reduced growth rates, increased fibronectin production, and abnormal morphologies similar to fibroblasts isolated from venous ulcers [104]. Such a model is a useful tool for direct analysis of the influences of venous hypertension on cells.

The use of multilayered compression therapy is the gold standard in the treatment of a venous ulcer [105]. If there is a lack of improvement over a 2- to 4-week period this is predictive of eventual lack of response to therapy and suggests the need for adjunctive methods to achieve success, such as oral pentoxifylline, tissue-engineered skin, or skin grafting [106]. An alternate treatment of patients with venous stasis ulcerations is a combination of oral and local Pycnogenol, a powerful antioxidant, shows a faster reduction in ulcerated area in comparison those receiving only an oral treatment [102].

\section{NEGATIVE PRESSURE TREATMENT}

Negative pressure treatment, called vacuum-assisted closure (VAC) therapy, or vacuum-assisted closure, is effective clinically on infected surgical wounds, traumatic wounds, pressure ulcers, wounds with exposed bone and hardware, diabetic foot ulcers, and venous stasis ulcers [107112]. It utilizes negative pressure to remove fluid from open wounds through a sealed dressing and tubing, which is connected to a collection container. VAC therapy increases wound blood flow, speeds the formation of granulation tissue, and decreases accumulation of fluid and bacteria and accelerate healing.

The optimal sub-atmospheric pressure for wound healing is approximately $125 \mathrm{~mm} \mathrm{Hg}$ using alternating pressure cycles of 5 minutes suction and 2 minutes without suction. The cyclical application of sub-atmospheric pressure alters the cytoskeleton of the cells in the wound bed, triggering a cascade of intracellular signals that increases the rate of cell division and the subsequent formation of granulation tissue. VAC therapy is also rapid and effective in promoting angiogenesis with the subsequent formation of healthy tissue [113]. Pressure ulcers in all of the categories investigated respond to some degree to VAC therapy [109, 113] with an average size reduction of 55\% [114]. VAC therapy induces a greater response than both alginate and hydrocolloid dressings [109].

Patients receiving negative pressure wound therapy experienced lower rates of hospitalization ( $35 \%$ versus $48 \%$ ) due to wound problems (5\% versus $14 \%$,), and emergent care for wound problems ( $0 \%$ versus $8 \%$ ) [110]. VAC leads to quicker closure for chronic wounds or in patients with diabetic foot and ankle ulcers, and wounds secondary to 
peripheral vascular disease, diabetes or peripheral vascular disease [107, 115], and significantly increases skin graft success rate when used as a bolster over the freshly skingrafted wound [116].

\section{SYSTEMIC HYPERBARIC OXYGEN THERAPY (HBO) VS. TOPICAL OXYGEN THERAPY}

Systemic hyperbaric oxygen therapy and topical oxygen are entirely different. Topical oxygen therapy uses an airtight chamber sealed around a limb or the trunk by a constriction / tourniquet device or by tape, while a high flow (usually 10 liters per minute) oxygen is introduced into the bag and over the wound with a pressure of over 1.0 atmosphere [117, 118].

Topical oxygen is advocated for the diffusion of oxygen into the wound adequate to enhance healing, and its delivery is less complex and expensive than hyperbaric oxygen. However, data from some topical oxygen therapy studies report a decreased collagen production and inhibition of fibroblast inhibition in wounds, which are considered evidence for improved wound healing, and there is little evidence for its benefits.

Inhalation of pure oxygen causes an increase in normal basal $\mathrm{PO}_{2}$ values, typically lower than $40 \mathrm{mmHg}$, to $\geq 100$ $\mathrm{mmHg}$, at least 3 times the basic value. Treatment of patients with diabetic foot ulcers with HBO therapy causes a doubling of the rate of ulcers healing [119], vs. a $48 \%$ increased rate of ulcer healing for conventionally treated patients. Thus, HBO therapy is valuable for treating selected cases of hypoxic diabetic foot ulcers by accelerating the rate of healing, reduces the need for amputation, and increases the number of wounds that are completely healed on longterm follow-up.

Systemic hyperbaric oxygen therapy involves 100\% oxygen presentation under 2.4 atmospheres of pressure, and induces both increased collagen production and fibroblast proliferation, which are considered evidence for improved wound healing. HBO treatment for 90 min daily for a total of 30 treatments results in healing with complete epithelialisation in $60 \%$ of the treatment group compared to $13 \%$ in the control group [120]. For diabetic ulcers, HBO induced a 4.6-fold decrease in the ulcer size in $70 \%$ of the patients at an average of 2.5 months [107]. Thus, HBO plus high pressure enhances the healing of ischemic, non-healing diabetic leg ulcers and appears to be a valuable adjunct to conventional therapy $[120,121]$.

Analysis of the pooled data from five trials on diabetic ulcers, showed a significant reduction in the risk of major amputation with HBO therapy, but no influence on ulcer healing and the rate of minor amputation [122]. However, it was concluded that for venous, arterial or pressure ulcers there was insufficient data to provide statistical evidence for the efficacy of HBO treatment [122].

\section{Hyperbaric Oxygen Plus Basic FGF}

HOB plus basic FGF induces the elimination of skin ulcer in legs that were refractory to conventional therapy $[123,124]$. The combined therapy induced proliferation of connective tissue of the ulcer tissues, especially collagen and non-collagenous protein suggesting that the healing was due to the proliferation of granulation tissues of the ulcer lesion [123].

\section{Electrical Stimulation}

Several forms of electrical stimulation have been tested for their efficacy in eliminating pressure ulcers, among which are bio-electrical stimulation therapy (BEST) and pulsed electromagnetic force stimulation (PEMF), also called interrupted direct current (IDC). The concept for their effectiveness is that the human body has an endogenous bioelectric system that enhances healing of bone fractures and soft-tissue wounds while another is that the stimulation induces bone to release a host of wound and bone healing factors.

Electrical stimulation has also reported to have no induce on wound healing [125], while in other studies electrical stimulation was shown to enhance the rate of pressure ulcer healing compared unstimulated controls [126] However, due to the great differences in the methodologies of electrical stimulation, and differences in electrical field forces used, from weak to high-voltage pulsed galvanic stimulation, and the small numbers of participants involved in most studies, further work is required to determine the validity of electrical stimulation in eliminating pressure ulcers.

It has been proposed that high voltage pulsed galvanic stimulation (HVPGS) restores sympathetic tone and vascular resistance below the level of the spinal cord lesion, and thereby may increase the perfusion pressure gradient in the capillary beds [127]. HVPGS has been shown to induce a $35 \%$ increase in sacral $\mathrm{PtcO}_{2}$, from a baseline level of 49 $\mathrm{mmHg}$ to $66 \mathrm{mmHg}$ after 30 minutes of stimulation on subjects lying supine [128].

\section{Negative Pressure and Electrical Stimulation}

Pressure ulcers may be prevented not only by reducing external pressure, but also by increasing the patient's resistance to pressure by directly influencing tissue oxygenation. High-voltage pulsed galvanic stimulation (75 $\mathrm{V}, 10 \mathrm{~Hz}$ ) applied to the back at spinal level T6 in spinalcord-injured persons lying supine raises sacral transcutaneous oxygen tension levels to the normal ranges [128]. Thus, high-voltage pulsed galvanic stimulation may be instrumental in preventing pressure ulcers in spinal-cordinjured persons and other groups at high risk [127]. Although both increase cutaneous blood flow, and promote the healing of pressure ulcers, there is no literature on the influences of using negative pressure and electrical stimulation parallel [129].

\section{Topical Hyperbaric Oxygen and Electrical Stimulation}

The influences of topical hyperbaric oxygen and electrical stimulation on Stage III or Stage IV pressure ulcers were studied in a small preliminary clinical trial, but no significant differences in healing were seen, compared to patients receiving topical hyperbaric oxygen alone [130].

\section{Pulsed Low-intensity Ultrasound}

Although its mechanism of action is not known and there are conflicting reports on its efficacy, pulsed low-intensity ultrasound is used clinically to enhance the healing rate of pressure ulcers $[25,131]$. In one small study, pulsed low- 
intensity ultrasound was administered to a patient with a Stage III pressure ulcer over the coccyx for 5 days a week for two consecutive weeks. The treatment resulted in significantly faster healing, wound surface area, (2.7-fold), than seen with placebo ultrasound treatment [132]. However, the healing was significantly faster during the baseline period compared to the pulsed low-intensity ultrasound period [132]. Thus, low-intensity ultrasound appears to have no significant effect on healing of the patient's pressure ulcer beyond that of the standard-care protocol [132].

\section{Activated Macrophages}

Activated macrophages play a major role in almost all stages of wound healing and it may be possible to use local application to ulcers to promote healing. However, prior to ulcer application the monocytes / macrophages must first be activated. This can be accomplished by application of hypoosmotic shock during the process of monocyte-concentrate preparation from a blood unit [133].

Differential gene expression of the hypo-osmotic shockactivated monocytes/macrophages by DNA microarray analysis shows a significant increased levels of expression of a number of genes directly involved in macrophage function and wound healing, such as gene expression of cytokines and receptors in the activated cells [133, 134]. This correlates with the observed secretion by activated macrophages of cytokines such as IL-1, IL-6, which are a part of the healing process. Thus, application of activated macrophages may be a technique that can be used to induce the wound healing process [133].

\section{Hormone Replacement Therapy}

Hormone replacement therapy (HRT) has been shown to have a protective effect on the occurrence of venous ulcers of the lower limbs of elderly patients compared to those who did not use HRT [135, 136].

\section{Human Fibroblast-derived Dermal Substitute}

Dermagraft (Smith \& Nephew) is a human neonatalderived bioengineered tissue comprised of human fibroblast dermal fibroblasts [137]. The chronic diabetic foot ulcers $(>6$ weeks) of patients treated for 12 weeks with Dermagraft resulted in a $60 \%$ increase in complete wound closure compared to the compared to the ulcers of patients treated conventional therapy alone [137-139]. Although the incidence of adverse events was similar for both the Dermagraft and control groups, the Dermagraft group experienced significantly fewer ulcer-related adverse events [138].

\section{Laser Treatment}

Near-infrared low-level laser therapy (LLLT) under temperature-controlled conditions have been tested for their influences on ulcer healing [140]. No evidence was found that justifies using low-level laser therapy as an adjuvant to the consensus decubitus ulcer treatment [140].

\section{Light Therapy}

Tests for the ability of multi-wavelength light therapy from a gallium-aluminum-arsenide laser source to influence overall healing of pressure ulcers found that it had no influence in ulcer healing rates [141].

\section{Ultrasound}

There is no evidence of benefit of ultrasound therapy in the treatment of pressure ulcers [131]. However, the possibility of beneficial or harmful effect cannot be ruled out due to the small number of trials, some with methodological limitations and small numbers of participants. Further research is needed in this area.

\section{Radiant Heat}

Warming a wound edge and periwound for 1-hour leads to increased skin temperature that persists for 15 minutes after warming [142]. This heating enhances the rate of healing of both acute and chronic wounds compared to standard treatment [143]. The mechanism of actions is likely to be an increased blood flow and thus increased oxygenations of the wound tissue.

\section{Polarized Light}

Pressure ulcers were exposed to polarized light for 2 weeks, consisting a $5 \mathrm{~min}$ daily therapy session, excluding weekends, for 10 days. The ulcers showed better healing compared to control ulcers [144].

\section{Dietary Supplements}

Good nutrition is critical to a patient's wound healing. For patients with pressure ulcers, an oral nutritional supplement, rich in protein and enriched with arginine, vitamin $\mathrm{C}$ and zinc, has been found to lead to a significant reduction in the area of pressure ulcers [145].

\section{Angiogenesis}

Improved microcirculation and angiogenesis of the skin is critical for wound healing [146-148]. Topically applied Phenytoin, a promoter of angiogenesis, substantially accelerates the rate of ulcer healing [149]. It acts by increasing lymphocytic infiltration of the phenytoin-treated lesion. Anti-CD31 immunohistochemistry revealed dense CD31+ lymphocytic infiltration and increased angiogenesis in phenytoin-treated, but not control lesions [149]. Thus, phenytoin appears to enhances wound healing by stimulating lymphocytic chemotaxis and up-regulation of angiogenesis [149]. Enhanced rates of ulcer healing can also be induced by induction of angiogenesis by implantation of bone marrow mononuclear cells (BM-MNCs), including endothelial progenitor cells [150].

Crystacide has been shown to improve microcirculation and decreases skin free radicals and could therefore play a significant role in wound healing [151]. Although antiseptics such as benzoyl peroxide (BP) are used as the first-line treatment for acne vulgaris, there is suboptimal skin tolerability. Crystacide (Mipharm, Milan, Italy) is a new formulation of hydrogen peroxide (HP) $1 \%$ in stabilized cream which has better skin tolerability than benzoyl peroxide [152].

Crystacide treatment provided to patients with chronic venous insufficiency and venous hypertension associated with ulcerations, resulted in increasing local $\mathrm{PO}_{2}$ in ulcers, and decreasing PFR and LDF (flux increase is associated with venous hypertension). It also led to a significant reduction in the size of ulcers after 10 days of treatment [151]. 


\section{Maggots for Debridement}

For centuries green bottle fly maggots, Phaenicia sericata, have been known to help to debride and heal wounds. Maggot therapy was first introduced in the USA in 1931 and was routinely used there until the mid-1940s in over 300 hospitals. With the advent of antimicrobiols, maggot therapy became rare until the early 1990s, when it was re-introduced into modern wound management practice in the USA, UK, and Israel in the treatment of wounds such as pressure sores and leg ulcers [6, 153], diabetic ulcers [154-156] gangrene [157], traumatic injuries [154, 158], burns [159], and surgical wounds [156, 160, 161]. The treatment involves the administration of sterile maggots (50$1000)$ to the wound two to five times weekly and replaced every 1-2 days. Complete debridement can be achieved in about $80 \%$ of the patients, compared to only $48 \%$ with conventionally treated wounds [162]. Within 3 weeks, maggot-treated wounds necrotic tissue is reduced to one third, and tissue granulation is doubled, compared to nonmaggot-treated wounds [162]. Thus, maggot therapy is a relatively rapid and effective treatment, including those caused by antibiotic-resistant strains of bacteria such as methicillin-resistant Staphylococcus aureus, particularly in large necrotic wounds requiring debridement and that are resistant to conventional treatment and conservative surgical intervention [162]. Although no significant risks or adverse events have been linked to the use of maggots, although their presence may increase pain levels in leg ulcers associated with ischemic disease $[162,163]$.

\section{ANTIBIOTICS}

Data does not support the routine use of systemic antibiotics for leg ulcers or diabetic foot ulcers without acute infection, although they may be useful as an adjunct to surgery for pilonidal sinuses. However, several topical preparations may be helpful, including dimethyl sulphoxide, silver sulphadiazine, benzoyl peroxide, oxyquinoline and gentamycin [14, 164].

\section{Honey}

The honey appears to act as an effective antibacterial, anti-inflammatory and deodorizing dressing. In a number of studies total wound healing was accomplished with the application of honey-impregnated alginate dressing to pressure ulcers $[165,166]$.

\section{Spasticity in SCI Patients}

Paraplegic and quadriplegic patients particularly those suffering from spinal cord injuries are at a high risk of developing pressure ulcerations. Patients with a pressure ulcer $(14.1 \%)$ were significantly more likely to have a contracture than patients without a pressure ulcer $(7.1 \%)$. Contractures and spasticity often contribute to the development of pressure ulcers by repeatedly exposing tissues to pressure through flexion of a joint. Contractures rigidly hold a joint in flexion, while spasticity subjects tissues to considerable repeated friction and shear forces. Contractures are also more common in patients with spasticity requiring medication (12\%) than without spasticity (8\%). Unlike pressure ulcers in geriatric patients, which usually can be controlled with pressure relieving devices and local wound care. Spasticity control in spinal cord injury patients should be included as a prerequisite for any treatment protocol of such patients [167]. Thus, there is significant importance in the early admission of spinal cord injury patients to a coordinated spinal cord injury center for the prevention of contractures.

\section{Wound Healing By Early Admittance, Intense and Comprehensive Care}

Critical to spinal cord patients' avoidance of pressure ulcers is their early admission to an organized, multidisciplinary spinal cord injury program. Patients admitted to such a program within 1 day of injury had statistically significant reductions in acute care and total lengths of stay coupled with a highly significant reduction in the incidence of pressure ulcers compared to patients who received their acute care services elsewhere and who were admitted to the system solely for rehabilitation. This included ventilator dependency and acute surgical procedure experience. In addition, the mortality rates of these patients were lower than those patients who were not admitted to an organized care system [168].

Medicare established a Quality Indicator System for pressure ulcer prediction and prevention [169]. National estimates of compliance with this process of care were: use of daily skin assessment, 94\%; use of pressure-reducing device, $7.5 \%$; documentation of being at risk, $22.6 \%$; repositioning for a minimum of 2 hours, $66.2 \%$; nutritional consultation, 34.3\%; stage 1 pressure ulcer staged, $20.2 \%$; and stage 2 or greater ulcer staged, 30.9\% [169]. These results indicated that that US hospitals and physicians have numerous opportunities to improve care related to pressure ulcer prediction and prevention.

\section{Costs}

The average medical cost to care for a single patient in the US due to pressure ulcers is estimated to be $\$ 400,000$ [170]. New Mexico Medicaid fee-for-service system incurred a total cost of approximately $\$ 3$ million annually for the treatment of the 4 categories of skin ulcers studied [171] and this was for only a fraction of the hospitalized population. The data showed that the majority of wounds were coded as pressure ulcers, which had the highest associated costs [171]. In England the annual cost is about $\$ 4.2$ billion, or $4 \%$ of the total National Health Service budget [172], while in the US annual cost related to pressure ulcer care are estimated at $\$ 10$ billion.

Clinicians now approach pressure ulcers as preventable rather than inevitable and view Certified Wound Ostomy Continence Nurses as resources and clinical experts for prevention and treatment. Overall quality of care and financial resource utilization has also improved substantially. However, there is considerable concern about the increased costs of changing from traditional wound care, e.g. hydrocolloids, to Vacuum Assisted Closure (VAC) for the treatment of pressure ulcer, diabetic foot ulcer and ulcus cruris. In Germany alone, it is estimated that the additional costs would be 5 billion Euros per annum only for materials. Cost-effectiveness analysis has shown that despite the extra costs involved in using hyperbaric oxygen, there could be a potential saving for the cost of treatment for each patient [120]. Additional staffing for patients also reduces the 
incidence of ulcer development and length of additional hospitalization and the healthcare saving cost more than offsets the expense of the additional staff [171]. Further, development of a reliable wound healing techniques, such as electrical stimulation and autologous growth and wound healing factors that enhances the speed and extent of healing would are likely to save considerably more than their costs in terms of lost labor and related expenses.

\section{PRESSURE ELIMINATION USING A NOVEL TECH- NIQUE}

We performed a spinal cord operation on a patient with a complete C6 spinal cord transection. Soon after the operation, the patient developed a pressure ulcer in the coccyx region, which became chronic, continuing to grow in diameter and in depth for one year, in spite of routine standard cleaning of the ulcer.

As part of our IRB-approved study, one year following the patient's surgery we applied a pulsed electromagnetic force (PEMF) simulator, obtained on the open market, above C6 to see whether the stimulation had any effect on the patient's neurological recovery. We observed no neurological changes. With the stimulator in this position, its most caudal end was located $45 \mathrm{~cm}$ from the cephalic edge of the pressure ulcer.

Within four days of initiating the PEMF stimulation, the tissue within the ulcer began to turn pinkish, and by one week the ulcer began to diminish in depth and diameter. After six weeks use of the stimulator, the ulcer was almost completely closed, and was completely closed by 8 weeks.

The extremely rapid change in the color of the tissue of the ulcer, and the shrinkage of the ulcer within one week of starting the PEMF stimulation, strongly suggests a positive correlation between the stimulation and elimination of the ulcer [173].

Over a distance of $45 \mathrm{~cm}$, the effective field force generated by the PEMF stimulator is calculated to be effectively zero. This makes it unlikely that the electrical stimulation was directly responsible for the observed improvement in the ulcer. Alternative explanations for the apparent influence of the stimulation on the ulcer are that the electrical stimulation acted on nerves in the region of the stimulator which innervated the ulcer region, or by paracrine effect, by inducing the release of growth factors into the blood stream that affected the pressure ulcer, such as the angiogenesis factors FGF-2 and VEGF.

Little is known about the field force required to reverse the growth of ulcers and induce their elimination. Therefore, a new clinical study is required to examine directly the electrical field forces and the distance from an ulcer at which they should be applied to induce pressure ulcer elimination. It will also be of interest to determine whether ulcer elimination via PEMF stimulation can be enhanced when combined with other techniques, such as hyperbaric oxygenation and application of neurotrophic and wound healing factors to the ulcer.

\section{CONCLUSIONS}

A number of techniques increase the healing rate of pressure ulcers. However, while many are only marginally effective, other techniques appear to be more effective. The most effective means for healing pressure ulcers appears to be packing an ulcer with platelet-rich fibrin, electrical stimulation, inhibiting metalloproteases, and hypobaric oxygen treatment. Although each of these techniques is effective by itself, further studies are required to determine the optimal effective application of technique. Although a very promising technique, there are no FDA-approved inhibiting metalloproteases available for testing, which makes this one of the four options not currently possible to test. Therefore, potential optimally effective combinations of techniques are the simultaneous application of wound packing with platelet-rich fibrin, electrical stimulation, and hypobaric oxygen treatment, for the most rapid and significant elimination of pressure ulcers. Optimal combinations of techniques should also be applied as soon as an ulcer begins to develop to reverse the process and prevent the developed of a penetrating ulcer. Such an approach would enormously reduce pain and suffering, the need for amputations, the duration of hospitalization, and the associated health care costs.

\section{REFERENCES}

[1] Sella, E.J.; Barrette, C. Staging of Charcot neuroarthropathy along the medial column of the foot in the diabetic patient. J. Foot Ankle Surg., 1999, 38, 34-40.

[2] Levine, J.M. Historical perspective on pressure ulcers: the decubitus ominosus of Jean-Martin Charcot. J. Am. Geriatr. Soc., 2005, 53, 1248-1251.

[3] Levine, J.M. Historical perspective: the neurotrophic theory of skin ulceration. J. Am. Geriatr. Soc., 1992, 40, 1281-1283.

[4] Levine, J.M. Wound care in the 21st century: lessons from ancient Egypt. J. Am. Med. Dir. Assoc., 2000, 1, 224-227.

[5] Niezgoda, J.A.; Mendez-Eastman, S. The effective management of pressure ulcers. Adv Skin Wound Care, 2006, 19 Suppl. 1, 3-15.

[6] Thomas, D.R. Prevention and treatment of pressure ulcers. J. Am. Med. Dir. Assoc., 2006, 7, 46-59.

[7] Ferrell, B.A.; Josephson, K.; Norvid, P.; Alcorn, H. Pressure ulcers among patients admitted to home care. J. Am. Geriatr. Soc., 2000, 48, 1042-1047.

[8] Berlowitz, D.R.; Brandeis, G.H.; Anderson, J.; Brand, H.K. Predictors of pressure ulcer healing among long-term care residents. J. Am. Geriatr. Soc., 1997, 45, 30-34.

[9] Langemo D.; Anderson, J.; Hanson, D.; Hunter, S.; Thompson, P.; Posthauer, M.E. Nutritional considerations in wound care. Adv. Skin Wound Care, 2006, 19, 297-298, 300, 303.

[10] Scivoletto, G.; Fuoco, U.; Morganti, B.; Cosentino, E.; Molinari, M. Pressure sores and blood and serum dysmetabolism in spinal cord injury patients. Spinal Cord, 2004, 42, 473-476.

[11] Keast, D.H.; Fraser, C. Treatment of chronic skin ulcers in individuals with anemia of chronic disease using recombinant human erythropoietin (EPO): a review of four cases. Ostomy Wound Manage, 2004, 50, 64-70.

[12] Theaker, C.; Mannan, M.; Ives, N.; Soni, N. Risk factors for pressure sores in the critically ill. Anaesthesia, 2000, 55, 221-224.

[13] Narsete, T.A.; Orgel, M.G.; Smith, D. Pressure sores. Am. Fam. Physician, 1983, 28, 135-139.

[14] Cannon B.C.; Cannon, J.P. Management of pressure ulcers. Am. J. Health. Syst. Pharm., 2004, 61, 1895-1905; quiz 1906-1897.

[15] Holewski, J.J.; Stess, R.M.; Graf, P.M.; Grunfeld, C. Aesthesiometry: quantification of cutaneous pressure sensation in diabetic peripheral neuropathy. J. Rehabil. Res. Dev., 1988, 25, 110 .

[16] Jay, R. Pressure and shear: their effects on support surface choice. Ostomy Wound Manage., 1995, 41, 36-38, 40-32, 44-35.

[17] Daniel, R.K.; Wheatley, D.; Priest, D. Pressure sores and paraplegia: an experimental model. Ann. Plast. Surg., 1985, 15, 4149.

[18] Lowthian, P. The classification and grading of pressure ulcers. 1987. J. Tissue Viability, 2005, 15, 15-18. 
[19] Nixon, J.; Cranny, G.; Bond, S. Pathology, diagnosis, and classification of pressure ulcers: comparing clinical and imaging techniques. Wound Repair Regen., 2005, 13, 365-372.

[20] Bethell, E. Controversies in classifying and assessing grade 1 pressure ulcers. Nurs. Times, 2003, 99, 73-75.

[21] Edwards, J.L.; Pandit, H.; Popat, M.T. Perioperative analgesia: a factor in the development of heel pressure ulcers? Br. J. Nurs., 2006, 15, S20-25.

[22] Todkar, M. Sciatic nerve block causing heel ulcer after total knee replacement in 36 patients. Acta Orthop. Belg., 2005, 71, 724-725.

[23] Apsingi, S.; Dussa, C.U. Can peripheral nerve blocks contribute to heel ulcers following total knee replacement? Acta Orthop. Belg., 2004, 70, 502-504.

[24] Celani, M.G.; Spizzichino, L.; Ricci, S.; Zampolini, M.; Franceschini, M. Spinal cord injury in Italy: A multicenter retrospective study. Arch. Phys. Med. Rehabil., 2001, 82, 589-596.

[25] Helberg, D.; Mertens, E.; Halfens, R.J.; Dassen, T. Treatment of pressure ulcers: results of a study comparing evidence and practice. Ostomy Wound Manage, 2006, 52, 60-72.

[26] Ehrenreich, M.; Ruszczak, Z. Update on Tissue-Engineered Biological Dressings. Tissue Eng., 2006, 12(9), 2407-24.

[27] Lahmann, N.; Halfens, R.J.; Dassen, T. Effect of non-response bias in pressure ulcer prevalence studies. J. Adv. Nurs., 2006, 55, 230236.

[28] Dellefield, M.E. Organizational correlates of the risk-adjusted pressure ulcer prevalence and subsequent survey deficiency citation in California nursing homes. Res. Nurs. Health, 2006, 29, 345-358.

[29] Phillips, D.; Davey, C. Wound cleaning versus wound disinfection: a challenging dilemma. Perspectives (Montclair), 1997, 21, 15-16.

[30] Villasin, J.V.; Vinson, J.A.; Igoe, M.B.; Hendricks, L. Management of skin tears and stage II skin ulcers with two topical regimens: a study of cost minimization. Adv. Ther., 1996, 13, 10-19.

[31] Xakellis ,G.C.; Chrischilles, E.A. Hydrocolloid versus saline-gauze dressings in treating pressure ulcers: a cost-effectiveness analysis. Arch. Phys. Med. Rehabil., 1992, 73, 463-469.

[32] Konya, C.; Sanada, H.; Sugama, J.; Okuwa, M.; Kitagawa, A. Does the use of a cleanser on skin surrounding pressure ulcers in older people promote healing? J Wound Care, 2005, 14, 169-171.

[33] Moore, Z.E.; Cowman, S. Wound cleansing for pressure ulcers. Cochrane Database Sys. Rev., 2005, CD004983.

[34] Dowsett, C. The use of silver-based dressings in wound care. Nurs. Stand, 2004, 19, 56-60.

[35] Frank C.; Bayoumi, I.; Westendorp, C. Approach to infected skin ulcers. Can. Fam. Physician, 2005, 51, 1352-1359.

[36] Brett, D.W. A discussion of silver as an antimicrobial agent: alleviating the confusion. Ostomy. Wound Manage, 2006, 52, 3441.

[37] Maume, S.; Van De Looverbosch, D.; Heyman, H.; Romanelli, M.; Ciangherotti, A.; Charpin, S. A study to compare a new selfadherent soft silicone dressing with a self-adherent polymer dressing in stage II pressure ulcers. Ostomy. Wound Manage., 2003, 49, 44-51.

[38] Coutts, P.; Sibbald, R.G. The effect of a silver-containing Hydrofiber dressing on superficial wound bed and bacterial balance of chronic wounds. Int. Wound J., 2005, 2, 348-356.

[39] Norkus, A.; Dargis, V.; Thomsen, J.K.; Harding, K.G.; Ivins, N.; Serra, N.; Torres de Castro, O.G.; Galindo, A.; Andersen, K.E.; Roed-Petersen, J.; Gottrup, F.; Blanco, J.L.; de Mena, M.A.; Hauschild, A.; Moll, I.; Svensson, A.; Carter, K. Use of a hydrocapillary dressing in the management of highly exuding ulcers: a comparative study. J. Wound Care, 2005, 14, 429-432.

[40] Bots, T.C.; Apotheker, B.F. The prevention of heel pressure ulcers using a hydropolymer dressing in surgical patients. J. Wound Care, 2004, 13, 375-378.

[41] Diehm, C.; Lawall, H. Evaluation of Tielle hydropolymer dressings in the management of chronic exuding wounds in primary care. Int. Wound J., 2005, 2, 26-35.

[42] Edwards, J. Use of Exu-Dry in the management of a variety of exuding wounds. Br. J. Nurs., 2001, 10, 815-818.

[43] Bale, S.; Baker, N.; Crook, H.; Rayman, A.; Rayman, G.; Harding, K.G. Exploring the use of an alginate dressing for diabetic foot ulcers. J. Wound Care, 2001, 10, 81-84.

[44] Meaume, S.; Vallet, D.; Morere, M.N.; Teot, L. Evaluation of a silver-releasing hydroalginate dressing in chronic wounds with signs of local infection. J. Wound Care, 2005, 14, 411-419.
[45] Donaghue, V.M.; Chrzan, J.S.; Rosenblum, B.I.; Giurini, J.M.; Habershaw, G.M.; Veves, A. Evaluation of a collagen-alginate wound dressing in the management of diabetic foot ulcers. Adv. Wound Care, 1998, 11, 114-119.

[46] Belmin, J.; Meaume, S.; Rabus, M.T.; Bohbot, S. Sequential treatment with calcium alginate dressings and hydrocolloid dressings accelerates pressure ulcer healing in older subjects: a multicenter randomized trial of sequential versus nonsequential treatment with hydrocolloid dressings alone. J. Am. Geriatr. Soc., 2002, 50, 269-274.

[47] Thomas, S. Alginate dressings in surgery and wound management-Part 1. J. Wound Care, 2000, 9, 56-60.

[48] Day, A.; Dombranski, S.; Farkas, C.; Foster, C.; Godin, J.; Moody, M.; Morrison, M.; Tamer, C. Managing sacral pressure ulcers with hydrocolloid dressings: results of a controlled, clinical study. Ostomy Wound Manage, 1995, 41, 52-54, 56, 58 passim.

[49] Ohura, N.; Ichioka, S.; Nakatsuka, T.; Shibata, M. Evaluating dressing materials for the prevention of shear force in the treatment of pressure ulcers. J. Wound Care, 2005, 14, 401-404.

[50] Parnell, L.K.; Ciufi, B.; Gokoo, C.F. Preliminary use of a hydrogel containing enzymes in the treatment of stage II and stage III pressure ulcers. Ostomy Wound Manage, 2005, 51, 50-60.

[51] Kaya, A.Z.; Turani, N.; Akyuz, M. The effectiveness of a hydrogel dressing compared with standard management of pressure ulcers. $J$. Wound Care, 2005, 14, 42-44.

[52] Graumlich, J.F.; Blough, L.S.; McLaughlin, R.G.; Milbrandt, J.C.; Calderon, C.L.; Agha, S.A.; Scheibel, L.W. Healing pressure ulcers with collagen or hydrocolloid: a randomized, controlled trial. $J$. Am. Geriatr. Soc., 2003, 51, 147-154.

[53] Lee, S.K.; Posthauer, M.E.; Dorner, B.; Redovian, V.; Maloney, M.J. Pressure ulcer healing with a concentrated, fortified, collagen protein hydrolysate supplement: a randomized controlled trial. Adv. Skin Wound Care, 2006, 19, 92-96.

[54] King, S. Catrix: an easy-to-use collagen treatment for wound healing. Br. J. Commun Nurs., 2005, 10, S31-34.

[55] Bou Torra J.E.; Soldevilla Agreda, J.J.; Martinez Cuervo, F.; Rueda Lopez, J. [Collagen powder dressing in the treatment of pressure ulcer. Multicenter comparative study assessing effectiveness and cost]. Rev. Enferm., 2002, 25, 50-57.

[56] Payne, W.G.; Ochs, D.E.; Meltzer, D.D.; Hill, D.P.; Mannari, R.J.; Robson, L.E.; Robson, M.C. Long-term outcome study of growth factor-treated pressure ulcers. Am. J. Surg., 2001, 181, 81-86.

[57] Nakanishi, A.; Hakamada, A.; Isoda, K.; Mizutani, H. Atelocollagen sponge and recombinant basic fibroblast growth factor combination therapy for resistant wounds with deep cavities. J. Dermatol., 2005, 32, 376-380.

[58] Tyrone, J.W.; Mogford, J.E.; Chandler, L.A.; Ma, C.; Xia, Y.; Pierce, G.F.; Mustoe, T.A. Collagen-embedded platelet-derived growth factor DNA plasmid promotes wound healing in a dermal ulcer model. J. Surg. Res., 2000, 93, 230-236.

[59] Streit, M.; Beleznay, Z.; Braathen, L.R. Topical application of the tumour necrosis factor-alpha antibody infliximab improves healing of chronic wounds. Int. Wound J., 2006, 3, 171-179.

[60] Murphy, M.O.; Ghosh, J.; Fulford, P.; Khwaja, N.; Halka, A.T.; Carter, A.; Turner, N.J.; Walker, M.G. Expression of growth factors and growth factor receptor in non-healing and healing ischaemic ulceration. Eur. J. Vasc. Endovasc. Surg., 2006, 31, 516-522.

[61] Philipp, K.; Riedel, F.; Sauerbier, M.; Hormann, K.; Germann, G. Targeting TGF-beta in human keratinocytes and its potential role in wound healing. Int. J. Mol. Med., 2004, 14, 589-593.

[62] Tian ,Y.W.; Stacey, M.C. Cytokines and growth factors in keratinocytes and sweat glands in chronic venous leg ulcers. An immunohistochemical study. Wound Repair Regen., 2003, 11, 316325.

[63] Faler, B.J.; Macsata, R.A.; Plummer, D.; Mishra, L.; Sidawy, A.N Transforming growth factor-beta and wound healing. Perspect. Vasc. Surg. Endovasc. Ther., 2006, 18, 55-62.

[64] Philipp K.; Riedel, F.; Germann, G.; Hormann, K.; Sauerbier, M. TGF-beta antisense oligonucleotides reduce mRNA expression of matrix metalloproteinases in cultured wound-healing-related cells. Int. J. Mol. Med., 2005, 15, 299-303.

[65] Wollina, U.; Gruner, M.; Koch, A.; Kostler, E.; Hubl, W.; Hanson, N.B.; Oshima, J. Topical PDGF-BB results in limited healing in a patient with Werner's syndrome and chronic leg ulcers. J. Wound Care, 2004, 13, 415-416. 
[66] Seveljevic-Jaran, D.; Cuzic, S.; Dominis-Kramaric, M.; Glojnaric, I.; Ivetic, V.; Radosevic, S., Parnham, M.J. Accelerated healing of excisional skin wounds by PL 14736 in alloxan-hyperglycemic rats. Skin Pharmacol. Physiol., 2006, 19, 266-274.

[67] Margolis, D.J.; Bartus, C.; Hoffstad, O.; Malay, S.; Berlin, J.A. Effectiveness of recombinant human platelet-derived growth factor for the treatment of diabetic neuropathic foot ulcers. Wound Repair Regen., 2005, 13, 531-536.

[68] Senet, P. Becaplermin gel (Regranex gel). Ann. Dermatol. Venereol., 2004, 131, 351-358.

[69] Crovetti, G.; Martinelli, G.; Issi, M.; Barone, M.; Guizzardi, M.; Campanati, B.; Moroni, M.; Carabelli, A. Platelet gel for healing cutaneous chronic wounds. Transfus. Apher. Sci., 2004, 30, 145151

[70] Kunimoto, B.T. Growth factors in wound healing: the next great innovation? Ostomy. Wound Manage., 1999, 45, 56-64; quiz 65-56.

[71] Miller, M.C.; Nanchahal, J. Advances in the modulation of cutaneous wound healing and scarring. BioDrugs, 2005, 19, 363381.

[72] Rees, R.S.; Robson, M.C.; Smiell, J.M.; Perry, B.H. Becaplermin gel in the treatment of pressure ulcers: a phase II randomized, double-blind, placebo-controlled study. Wound Repair Regen., 1999, 7, 141-147.

[73] Bernabei, R.; Landi, F.; Bonini, S.; Onder, G.; Lambiase, A.; Pola, R.; Aloe, L. Effect of topical application of nerve-growth factor on pressure ulcers. Lancet, 1999, 354, 307.

[74] Landi, F.; Aloe, L.; Russo, A.; Cesari, M.; Onder, G.; Bonini, S.; Carbonin, P.U.; Bernabei, R. Topical treatment of pressure ulcers with nerve growth factor: a randomized clinical trial. Ann. Intern. Med., 2003, 139, 635-641.

[75] Graiani, G.; Emanueli, C.; Desortes, E.; Van Linthout, S.; Pinna, A.; Figueroa, C.D.; Manni, L.; Madeddu, P. Nerve growth factor promotes reparative angiogenesis and inhibits endothelial apoptosis in cutaneous wounds of Type 1 diabetic mice. Diabetologia, 2004, 47, 1047-1054.

[76] Aloe, L. Nerve growth factor, human skin ulcers and vascularization. Our experience. Prog. Brain Res., 2004, 146, 515522 .

[77] Cellini, M.; Bendo, E.; Bravetti, G.O.; Campos, E.C. The Use of Nerve Growth Factor in Surgical Wound Healing of the Cornea. Ophthalmic Res., 2006, 38, 177-181.

[78] Lambiase, A.; Manni, L.; Rama, P.; Bonini, S. Clinical application of nerve growth factor on human corneal ulcer. Arch. Ital. Biol., 2003, 141, 141-148.

[79] Generini, S.; Tuveri, M.A.; Matucci Cerinic, M.; Mastinu, F.; Manni, L.; Aloe, L. Topical application of nerve growth factor in human diabetic foot ulcers. A study of three cases. Exp. Clin. Endocrinol. Diabetes, 2004, 112, 542-544.

[80] Fu, X.; Shen, Z.; Chen, Y.; Xie, J.; Guo, Z.; Zhang, M.; Sheng, Z. Recombinant bovine basic fibroblast growth factor accelerates wound healing in patients with burns, donor sites and chronic dermal ulcers. Chin. Med. J. (Engl)., 2000, 113, 367-371.

[81] Muneuchi, G.; Suzuki, S.; Moriue, T.; Igawa, H.H. Combined treatment using artificial dermis and basic fibroblast growth factor (bFGF) for intractable fingertip ulcers caused by atypical burn injuries. Burns, 2005, 31, 514-517.

[82] Asai, J.; Takenaka, H.; Ichihashi, K.; Ueda, E.; Katoh, N.; Kishimoto, S. Successful treatment of diabetic gangrene with topical application of a mixture of peripheral blood mononuclear cells and basic fibroblast growth factor. J. Dermatol., 2006, 33, 349-352.

[83] Yamanaka, K.; Inaba, T.; Nomura, E.; Hurwitz, D.; Jones, D.A.; Hakamada, A.; Isoda, K.; Kupper, T.S.; Mizutani, H. Basic fibroblast growth factor treatment for skin ulcerations in scleroderma. Cutis, 2005, 76, 373-376.

[84] Gonul, B.; Akbulut, K.G.; Ozer, C.; Yetkin, G.; Celebi, N. The role of transforming growth factor alpha formulation on aspirin-induced ulcer healing and oxidant stress in the gastric mucosa. Surg. Today, 2004, 34, 1035-1040.

[85] Hirshberg, J.; Coleman, J.; Marchant, B.; Rees, R.S. TGF-beta3 in the treatment of pressure ulcers: a preliminary report. Adv. Skin Wound Care, 2001, 14, 91-95.

[86] Perez-Aisa, A.; Sopena, F.; Arceiz, E.; Ortego, J.; Sainz, R.; Lanas, A. Effect of exogenous administration of transforming growth factor-beta and famotidine on the healing of duodenal ulcer under the impact of indomethacin. Dig. Liver Dis., 2003, 35, 397-403.

[87] al-Momen, A.K. Recombinant human erythropoietin induced rapid healing of a chronic leg ulcer in a patient with sickle cell disease. Acta. Haematol., 1991, 86, 46-48.

[88] Russell, L. The importance of patients' nutritional status in wound healing. Br. J. Nurs., 2001, 10, S42, S44-49.

[89] Patel, G.K. The role of nutrition in the management of lower extremity wounds. Int. J. Low Extrem. Wounds, 2005, 4, 12-22.

[90] MacKay, D.; Miller, A.L. Nutritional support for wound healing. Altern. Med. Rev., 2003, 8, 359-377.

[91] Jais, A.M.; McCulloch, R.; Croft, K. Fatty acid and amino acid composition in haruan as a potential role in wound healing. Gen. Pharmacol., 1994, 25, 947-950.

[92] Langkamp-Henken, B.; Hudgens, J.; Stechmiller, J.K.; HerrlingerGarcia, K.A. Mini nutritional assessment and screening scores are associated with nutritional indicators in elderly people with pressure ulcers. J. Am. Diet. Assoc., 2005, 105, 1590-1596.

[93] Declair, V. The usefulness of topical application of essential fatty acids (EFA) to prevent pressure ulcers. Ostomy Wound Manage, 1997, 43, 48-52, 54.

[94] Salmela, M.T.; Pender, S.L.; Karjalainen-Lindsberg, M.L.; Puolakkainen, P.; Macdonald, T.T.; Saarialho-Kere, U. Collagenase-1 (MMP-1), matrilysin-1 (MMP-7), and stromelysin-2 (MMP-10) are expressed by migrating enterocytes during intestinal wound healing. Scand. J. Gastroenterol., 2004, 39, 1095-1104.

[95] Ladwig, G.P.; Robson, M.C.; Liu, R.; Kuhn, M.A.; Muir, D.F.; Schultz, G.S. Ratios of activated matrix metalloproteinase-9 to tissue inhibitor of matrix metalloproteinase-1 in wound fluids are inversely correlated with healing of pressure ulcers. Wound Repair Regen., 2002, 10, 26-37.

[96] Hieta, N.; Impola, U.; Lopez-Otin, C.; Saarialho-Kere, U.; Kahari, V.M. Matrix metalloproteinase-19 expression in dermal wounds and by fibroblasts in culture. J. Invest. Dermatol., 2003, 121, 9971004.

[97] Chang, J.H.; Kook, M.C.; Lee, J.H.; Chung, H.; Wee, W.R. Effects of synthetic inhibitor of metalloproteinase and cyclosporin A on corneal haze after excimer laser photorefractive keratectomy in rabbits. Exp. Eye Res., 1998, 66, 389-396.

[98] Sotozono, C.; He, J.; Tei, M.; Honma, Y.; Kinoshita, S. Effect of metalloproteinase inhibitor on corneal cytokine expression after alkali injury. Invest. Ophthalmol. Vis. Sci., 1999, 40, 2430-2434.

[99] Xue, M.; Le, N.T.; Jackson, C.J. Targeting matrix metalloproteases to improve cutaneous wound healing. Expert Opin. Ther. Targets, 2006, 10, 143-155.

[100] Viamontes, L.; Temple, D.; Wytall, D.; Walker, A. An evaluation of an adhesive hydrocellular foam dressing and a self-adherent soft silicone foam dressing in a nursing home setting. Ostomy Wound Manage., 2003, 49, 48-52, 54-46, 58.

[101] White ,J.V.; Ryjewski, C. Chronic venous insufficiency. Perspect Vasc. Surg. Endovasc. Ther., 2005, 17, 319-327.

[102] Belcaro, G.; Cesarone, M.R.; Errichi, B.; M.Ledda, A.; Di Renzo, A.; Stuard, S.; Dugall, M.; Pellegrini, L.; Rohdewald, P.; Ippolito, E.; Ricci, A.; Cacchio, M.; Ruffini, I.; Fano, F.; Hosoi, M. Venous ulcers: microcirculatory improvement and faster healing with local use of Pycnogenol. Angiology, 2005, 56, 699-705.

[103] Stanley, A.C.; Fernandez, N.N.; Lounsbury, K.M.; Corrow, K.; Osler, T.; Healey, C.; Forgione, P.; Shackford, S.R.; Ricci, M.A. Pressure-induced cellular senescence: a mechanism linking venous hypertension to venous ulcers. J. Surg. Res., 2005, 124, 112-117.

[104] Healey, C.; Forgione, P.; Lounsbury, K.M.; Corrow, K.; Osler, T.; Ricci, M.A.; Stanley, A. A new in vitro model of venous hypertension: the effect of pressure on dermal fibroblasts. J. Vasc. Surg., 2003, 38, 1099-1105.

[105] Brem, H.; Balledux, J.; Sukkarieh, T.; Carson, P.; Falanga, V. Healing of venous ulcers of long duration with a bilayered living skin substitute: results from a general surgery and dermatology department. Dermatol. Surg., 2001, 27, 915-919.

[106] De Araujo, T.S.; Hexsel, C.L.; Kirsner, R.S. Treatment of Venous Ulcers. Curr. Treat. Options Cardiovasc. Med., 2005, 7, 131-138.

[107] Mendonca, D.A.; Cosker, T.; Makwana, N.K. Vacuum-assisted closure to aid wound healing in foot and ankle surgery. Foot Ankle Int., 2005, 26, 761-766.

[108] Adamkova, M.; Tymonova, J.; Zamecnikova, I.; Kadlcik, M.; Klosova, H. First experience with the use of vacuum assisted 
closure in the treatment of skin defects at the burn center. Acta. Chir. Plast., 2005, 47, 24-27.

[109] Smith, N. The benefits of VAC therapy in the management of pressure ulcers. Br. J. Nurs., 2004, 13, 1359-1365.

[110] Schwien, T.; Gilbert, J.; Lang, C. Pressure ulcer prevalence and the role of negative pressure wound therapy in home health quality outcomes. Ostomy Wound Manage, 2005, 51, 47-60.

[111] Stetter C.; Plaza, T.; von den Driesch, P. Skin grafting of a chronic leg ulcer with combined Versajet-V.A.C. therapy. J. Dtsch. Dermatol. Ges., 2006, 4, 739-742.

[112] Stechmiller, J.K.; Kilpadi, D.V.; Childress, B.; Schultz, G.S. Effect of Vacuum-Assisted Closure Therapy on the expression of cytokines and proteases in wound fluid of adults with pressure ulcers. Wound Repair Regen., 2006, 14, 371-374.

[113] Loree, S.; Dompmartin, A.; Penven, K.; Harel, D.; Leroy, D. Is Vacuum Assisted Closure a valid technique for debriding chronic leg ulcers? J. Wound Care, 2004, 13, 249-252.

[114] Isago, T.; Nozaki, M.; Kikuchi, Y.; Honda, T.; Nakazawa, H. Negative-pressure dressings in the treatment of pressure ulcers. $J$. Dermatol., 2003, 30, 299-305.

[115] Abdul-Ghani, M.; Nawaf, G.; Nawaf, F.; Itzhak, B.; Minuchin, O.; Vardi, P. Increased prevalence of microvascular complications in type 2 diabetes patients with the metabolic syndrome. Isr. Med. Assoc. J., 2006, 8, 378-382.

[116] Venturi, M.L.; Attinger, C.E.; Mesbahi, A.N.; Hess, C.L.; Graw, K.S. Mechanisms and clinical applications of the vacuum-assisted closure (VAC) Device: a review. Am. J. Clin. Dermatol., 2005, 6, 185-194.

[117] Lipsky, B.A.; Berendt, A.R.; Deery, H.G.; Embil, J.M.; Joseph, W.S.; Karchmer, A.W.; LeFrock, J.L.; Lew, D.P.; Mader, J.T.; Norden, C.; Tan, J.S. Diagnosis and treatment of diabetic foot infections. Plast. Reconstr. Surg., 2006, 117, 212S-238S.

[118] Feldmeier, J.J.; Hopf, H.W.; Warriner, R.A.; 3rdFife, C.E.; Gesell, L.B.; Bennett, M. UHMS position statement: topical oxygen for chronic wounds. Undersea. Hyperb. Med., 2005, 32, 157-168.

[119] Kalani, M.; Jorneskog, G.; Naderi, N.; Lind, F.; Brismar, K. Hyperbaric oxygen (HBO) therapy in treatment of diabetic foot ulcers. Long-term follow-up. J. Diabetes Complications, 2002, 16, 153-158.

[120] Abidia, A.; Laden, G.; Kuhan, G.; Johnson, B.F.; Wilkinson, A.R.; Renwick, P.M.; Masson, E.A.; McCollum, P.T. The role of hyperbaric oxygen therapy in ischaemic diabetic lower extremity ulcers: a double-blind randomised-controlled trial. Eur. J. Vasc. Endovasc. Surg., 2003, 25, 513-518.

[121] Kranke, P.; Bennett, M.; Roeckl-Wiedmann, I.; Debus, S. Hyperbaric oxygen therapy for chronic wounds. Cochrane Database Syst. Rev., 2004, CD004123.

[122] Roeckl-Wiedmann, I.; Bennett, M.; Kranke, P. Systematic review of hyperbaric oxygen in the management of chronic wounds. Br. J. Surg., 2005, 92, 24-32.

[123] Nakada, T.; Saito, Y.; Chikenji, M.; Koda, S.; Higuchi, M.; Kawata, K.; Ishida, S.; Takahashi, S.; Kondo, S.; Kubota, Y.; Kubota, I.; Shimizu, Y. Therapeutic outcome of hyperbaric oxygen and basic fibroblast growth factor on intractable skin ulcer in legs: preliminary report. Plast. Reconstr. Surg., 2006, 117, 646-651; discussion 652-643.

[124] Wu, L.; Pierce, G.F.; Ladin, D.A.; Zhao, L.L.; Rogers, D.; Mustoe, T.A. Effects of oxygen on wound responses to growth factors: Kaposi's FGF, but not basic FGF stimulates repair in ischemic wounds. Growth Factors, 1995, 12, 29-35.

[125] Olyaee Manesh, A.; Flemming, K.; Cullum, N.A.; Ravaghi, H. Electromagnetic therapy for treating pressure ulcers. Cochrane Database Syst. Rev., 2006, CD002930.

[126] Hampton, S.; Collins, F. Treating a pressure ulcer with bio-electric stimulation therapy. Br. J. Nurs., 2006, 15, S14-18.

[127] Mawson, A.R.; Siddiqui, F.H.; Biundo, J.J. Jr. Enhancing host resistance to pressure ulcers: a new approach to prevention. Prev. Med., 1993, 22, 433-450.

[128] Mawson, A.R.; Siddiqui, F.H.; Connolly, B.J.; Sharp, C.J.; Stewart, G.W.; Summer, W.R.; Biundo, J.J., Jr. Effect of high voltage pulsed galvanic stimulation on sacral transcutaneous oxygen tension levels in the spinal cord injured. Paraplegia, 1993, 31, 311319.
[129] Moreno-Gimenez, J.C.; Galan-Gutierrez, M.; Jimenez-Puya, R. [Treatment of chronic ulcers]. Actas Dermosifiliogr, 2005, 96, 133146.

[130] Edsberg, L.E.; Brogan, M.S.; Jaynes, C.D.; Fries, K. Topical hyperbaric oxygen and electrical stimulation: exploring potential synergy. Ostomy Wound Manage, 2002, 48, 42-50.

[131] Baba-Akbari Sari, A.; Flemming, K.; Cullum, N.A.; Wollina, U. Therapeutic ultrasound for pressure ulcers. Cochrane Database Syst. Rev., 2006, 3, CD001275.

[132] Selkowitz, D.M.; Cameron, M.H.; Mainzer, A.; Wolfe, R. Efficacy of pulsed low-intensity ultrasound in wound healing: a single-case design. Ostomy. Wound Manage., 2002, 48, 40-44, 46-50.

[133] Frenkel ,O.; Shani, E.; Ben-Bassat, I.; Brok-Simoni, F.; RozenfeldGranot, G.; Kajakaro, G.; Rechavi, G.; Amariglio, N.; Shinar, E.; Danon, D. Activated macrophages for treating skin ulceration: gene expression in human monocytes after hypo-osmotic shock. Clin. Exp. Immunol., 2002, 128, 59-66.

[134] Black, J. Tissue oxygen perfusion and pressure ulcer healing. Plast. Surg. Nurs., 2000, 20, 10-14.

[135] Margolis, D.J.; Knauss, J.; Bilker, W. Hormone replacement therapy and prevention of pressure ulcers and venous leg ulcers. Lancet, 2002, 359, 675-677.

[136] Berard, A.; Kahn, S.R.; Abenhaim, L. Is hormone replacement therapy protective for venous ulcer of the lower limbs? Pharmacoepidemiol. Drug Saf., 2001, 10, 245-251.

[137] Marston, W.A. Dermagraft, a bioengineered human dermal equivalent for the treatment of chronic nonhealing diabetic foot ulcer. Expert Rev. Med. Devices, 2004, 1, 21-31.

[138] Marston, W.A.; Hanft, J.; Norwood, P.; Pollak, R. The efficacy and safety of Dermagraft in improving the healing of chronic diabetic foot ulcers: results of a prospective randomized trial. Diabetes Care, 2003, 26, 1701-1705.

[139] Omar, A.A.; Mavor, A.I.; Jones, A.M.; Homer-Vanniasinkam, S. Treatment of venous leg ulcers with Dermagraft. Eur. J. Vasc. Endovasc. Surg., 2004, 27, 666-672.

[140] Lanzafame, R.J.; Stadler, I.; Coleman, J.; Haerum, B.; Oskoui, P.; Whittaker, M.; Zhang, R.Y. Temperature-controlled 830-nm lowlevel laser therapy of experimental pressure ulcers. Photomed. Laser Surg., 2004, 22, 483-488.

[141] Taly, A.B.; Sivaraman Nair, K.P.; Murali, T.; John, A. Efficacy of multiwavelength light therapy in the treatment of pressure ulcers in subjects with disorders of the spinal cord: A randomized doubleblind controlled trial. Arch. Phys. Med. Rehabil., 2004, 85, 16571661.

[142] Whitney, J.D.; Salvadalena, G.; Higa, L.; Mich, M. Treatment of pressure ulcers with noncontact normothermic wound therapy: healing and warming effects. J. Wound Ostomy Continence Nurs., 2001, 28, 244-252.

[143] Price, P.; Bale, S.; Crook, H.; Harding, K.G. The effect of a radiant heat dressing on pressure ulcers. J. Wound Care, 2000, 9, 201-205.

[144] Iordanou, P.; Baltopoulos, G.; Giannakopoulou, M.; Bellou, P.; Ktenas, E. Effect of polarized light in the healing process of pressure ulcers. Int. J. Nurs. Pract., 2002, 8, 49-55.

[145] Frias Soriano, L.; Lage Vazquez, M.A.; Maristany, C.P.; Xandri Graupera, J.M.; Wouters-Wesseling, W.; Wagenaar, L. The effectiveness of oral nutritional supplementation in the healing of pressure ulcers. J. Wound Care, 2004, 13, 319-322.

[146] Patel, S.; Knapp, C.F.; Donofrio, J.C.; Salcido, R. Temperature effects on surface pressure-induced changes in rat skin perfusion: implications in pressure ulcer development. J. Rehabil. Res. Dev., 1999, 36, 189-201.

[147] de Graaff, J.C.; Ubbink, D.T.; van der Spruit, J.A.; Lagarde, S.M.; Jacobs, M.J. Influence of peripheral arterial disease on capillary pressure in the foot. J. Vasc. Surg., 2003, 38, 1067-1074.

[148] Bauer, S.M.; Bauer, R.J.; Velazquez, O.C. Angiogenesis, vasculogenesis, and induction of healing in chronic wounds. Vasc. Endovasc Surg., 2005, 39, 293-306.

[149] Pitiakoudis, M.; Giatromanolaki, A.; Iliopoulos, I.; Tsaroucha, A.K.; Simopoulos, C.; Piperidou, C. Phenytoin-induced lymphocytic chemotaxis, angiogenesis and accelerated healing of decubitus ulcer in a patient with stroke. J. Int. Med. Res., 2004, 32, 201-205.

[150] Koshikawa, M.; Shimodaira, S.; Yoshioka, T.; Kasai, H.; Watanabe, N.; Wada, Y.; Seto, T.; Fukui, D.; Amano, J.; Ikeda, U. Therapeutic angiogenesis by bone marrow implantation for critical 
hand ischemia in patients with peripheral arterial disease: a pilot study. Curr. Med. Res. Opin., 2006, 22, 793-798.

[151] Belcaro, G.; Cesarone, M.R.; Nicolaides, A.N.; Geroulakos, G.; Di Renzo, A.; Milani, M.; Ricci, A.; Brandolini, R.; Dugall, M.; Ruffini, I.; Cornelli, U.; Griffin, M. Improvement of microcirculation and healing of venous hypertension and ulcers with Crystacide. Evaluation of free radicals, laser Doppler flux and $\mathrm{PO}$. A prospective-randomized-controlled study. Angiology, 2003, $54,325-330$

[152] Capizzi, R.; Landi, F.; Milani, M.; Amerio, P. Skin tolerability and efficacy of combination therapy with hydrogen peroxide stabilized cream and adapalene gel in comparison with benzoyl peroxide cream and adapalene gel in common acne. A randomized, investigator-masked, controlled trial. Br. J. Dermatol., 2004, 151, 481-484.

[153] Sherman, R.A.; Wyle, F.; Vulpe, M. Maggot therapy for treating pressure ulcers in spinal cord injury patients. J. Spinal Cord Med., 1995, 18, 71-74.

[154] Jones ,M.; Thomas, S. Larval therapy. Nurs. Stand, 2000, 14, 4751 ; quiz 53-44.

[155] Lodge, A.; Jones, M.; Thomas, S. Maggots 'n' chips: a novel approach to the treatment of diabetic ulcers. Br. J. Commun Nurs., 2006, 11, S23-26.

[156] Fear, M. The use of maggots as a new treatment in the community. Nurs. Times, 2004, 100, 48-50.

[157] Mumcuoglu, K.Y.; Lipo, M.; Ioffe-Uspensky, I.; Miller, J.; Galun, R. [Maggot therapy for gangrene and osteomyelitis]. Harefuah, 1997, 132, 323-325, 382.

[158] Thomas, S.; Jones, M.; Wynn, K.; Fowler, T. The current status of maggot therapy in wound healing. Br. J. Nurs., 2001, 10, S5-8, S10, S12.

[159] Namias, N.; Varela, J.E.; Varas, R.P.; Quintana, O.; Ward, C.G. Biodebridement: a case report of maggot therapy for limb salvage after fourth-degree burns. J. Burn Care Rehabil., 2000, 21, 254257.

[160] Jones, M.; Champion, A. Nature's way. Nurs. Times, 1998, 94, 75, 78.
[161] Young, T. Maggot therapy in wound management. Commun. Nurs., 1997, 3, 43-45.

[162] Sherman, R.A. Maggot versus conservative debridement therapy for the treatment of pressure ulcers. Wound Repair Regen., 2002, 10, 208-214.

[163] Mumcuoglu, K.Y.; Ingber, A.; Gilead, L.; Stessman, J.; Friedmann, R.; Schulman, H.; Bichucher, H.; Ioffe-Uspensky, I.; Miller, J.; Galun, R.; Raz, I. Maggot therapy for the treatment of intractable wounds. Int. J. Dermatol., 1999, 38, 623-627.

[164] O'Meara, S.M.; Cullum, N.A.; Majid, M.; Sheldon, T.A. Systematic review of antimicrobial agents used for chronic wounds. Br. J. Surg., 2001, 88, 4-21.

[165] French, V.M.; Cooper, R.A.; Molan, P.C. The antibacterial activity of honey against coagulase-negative staphylococci. J. Antimicrob. Chemother., 2005, 56, 228-231.

[166] Molan, P.C. The evidence supporting the use of honey as a wound dressing. Int. J. Low Extrem. Wounds, 2006, 5, 40-54.

[167] Atiyeh, B.S.; Hayek, S.N. Pressure sores with associated spasticity: a clinical challenge. Int Wound J., 2005, 2, 77-80.

[168] DeVivo, M.J.; Kartus, P.L.; Stover, S.L.; Fine, P.R. Benefits of early admission to an organised spinal cord injury care system Paraplegia, 1990, 28, 545-555.

[169] Lyder, C.H.; Preston, J.; Grady, J.N.; Scinto, J.; Allman, R. Bergstrom, N.; Rodeheaver, G. Quality of care for hospitalized medicare patients at risk for pressure ulcers. Arch. Intern. Med., 2001, 161, 1549-1554

[170] Khan, M.N.; Davies, C.G. Advances in the management of leg ulcers--the potential role of growth factors. Int. Wound J., 2006, 3 , 113-120.

[171] Kumar, R.N.; Gupchup, G.V.; Dodd, M.A.; Shah, B.; Iskedjian, M.; Einarson, T.R.; Raisch, D.W. Direct health care costs of 4 common skin ulcers in New Mexico Medicaid fee-for-service patients. Adv. Skin Wound Care, 2004, 17, 143-149.

[172] Bennett, G.; Dealey, C.; Posnett, J. The cost of pressure ulcers in the UK. Age Ageing, 2004, 33, 230-235.

[173] Sosa I.J.; Reyes, O.; Kuffler, D.P. Elimination of a pressure ulcer with electrical stimulation--a case study. P. R. Health Sci. J., 2008, $27,175-179$.

(C) Damien P. Kuffler; Licensee Bentham Open.

This is an open access article licensed under the terms of the Creative Commons Attribution Non-Commercial License (http://creativecommons.org/licenses/by-nc/3.0/) which permits unrestricted, non-commercial use, distribution and reproduction in any medium, provided the work is properly cited. 